\title{
COLLABORATION CAPABILITY IN VIRTUAL TEAMS: EXAMINING THE INFLUENCE ON DIVERSITY AND INNOVATION
}

\author{
FADI S. BATARSEH* ${ }^{*}$ and JOHN M. USHER ${ }^{\dagger}$ \\ Department of Industrial and Systems Engineering \\ Mississippi State University, Starkville, MS, USA \\ *b150@msstate.edu \\ †usher@engr.msstate.edu \\ JOSHUA J. DASPIT \\ Department of Management and Information Systems \\ Mississippi State University, Starkville, MS, USA \\ josh.daspit@msstate.edu
}

Published 28 November 2016

\begin{abstract}
Virtual teams are being increasingly utilised in industry given their ability to bring together diverse knowledge and experience from individuals who are not geographically proximal. Having a diversity of knowledge within virtual teams is noted to benefit innovation outcomes; however, leveraging the benefits of diversity (both deep and functional-level) is likely to require a capability to facilitate collaboration among team members. In this study, we empirically validate a measure of collaboration capability (CCAP) and examine its role in enhancing the benefits of diversity on innovation within virtual teams. Using a sample of 375 design and software engineers working in virtual teams from a hightech firm in Silicon Valley, we find that CCAP significantly moderates the relationship between functional-level diversity and innovation, but no significant influence is found for a similar moderating influence on deep-level diversity and innovation. The implications for the study of virtual teams are discussed and recommendations are offered for organisations using virtual teams.
\end{abstract}

Keywords: Collaboration capability; virtual teams; innovation; deep-level diversity; functional-level diversity.

This is an Open Access article published by World Scientific Publishing Company. It is distributed under the terms of the Creative Commons Attribution 4.0 (CC-BY) License. Further distribution of this work is permitted, provided the original work is properly cited. 


\section{Introduction}

Globalisation has opened new possibilities for establishing and maintaining competitive advantage. As firms operate in competitive and tumultuous global markets, innovation and collaboration are critical to success (Matthew and Sternberg, 2006). Technology has advanced in ways that support the creation of teams of experts who are remotely located from one another, and the use of virtual teams enables individuals to collaborate, overcoming the limitations of geography and time zones. A report in 2011 from analyst firm Gartner, Inc., projected that by 2015, about 75\% of knowledge-based project work will be completed by distributed virtual teams, but the complexity of virtual projects elevates the level of risk associated with the technology (Gartner, 2011).

The creation of these teams provides unprecedented opportunities for collaboration, innovation, and corporate effectiveness (Goerzen and Beamish, 2005; Hosseini and Chileshe, 2013; Rogbeer et al., 2014), and the use of virtual teams also means that relocating personnel is no longer required. Virtual teams with a flexible and configurable infrastructure often reduce costs, save time, and increase productivity (Anderson and Carletta, 2007; Carmel and Tjia, 2005; Martinic et al., 2012). By having team members located across several time zones, team members can advance the project within their respective workdays, providing continual progress to a project (Vaccaro et al., 2009). Virtual teams are also noted as a means to increase diverse knowledge resources by improving access to experts who contribute to the exploration of creative and innovative solutions (Alavi and Tiwana, 2002; Duarte et al., 2011; Griffith et al., 2003).

While virtual teams are increasingly becoming the solution for globalisation and increased competitive advantages, significant challenges remain in managing collaboration within virtual teams. These challenges are due to cultural, technical, and experiential differences as well as difficulty in developing trust and shared understanding among team members who are not within the same physical proximity. Such obstacles pose high risks and create uncertainty in the implementation of virtual teams, and if not appropriately managed, the virtual team may experience poor performance, intra-group conflict, miscommunication, and lack of trust (Ferrazzi, 2014; Pinjani and Palvia, 2013).

Although the diversity of knowledge created by involving members from diverse backgrounds and experiences creates a bundle of potentially valuable resources for the team, if team member diversity is not properly managed, such benefits may become liabilities. We suggest that to enhance the beneficial effects of diversity on virtual team outcomes, the team must develop relationally oriented capabilities. In other words, to successfully integrate the heterogeneous knowledge resources present among team members, the virtual team must develop trust, communication, and commitment among its members. The capability to build and 
manage relationships based on trust, communication, and commitment is noted as the collaboration capability (CCAP) by Blomqvist and Levy (2006).

The primary objective of this study is to investigate the role of CCAP within the virtual team. Specifically, we examine how CCAP positively moderates the influence of two types of diversity (deep and functional) on team innovation. Using a sample of virtual team members from a high-tech firm in Silicon Valley, we find that CCAP significantly influences the relationship between functional-level diversity and team innovation, while CCAP is found to not significantly influence relationship between deep-level diversity and team innovation.

The findings of this study offer numerous contributions to the study of virtual teams. First, this study offers empirical validation of the CCAP construct. CCAP is conceptually theorised by Blomqvist and Levy (2006) as a relationally oriented capability, and in this study, we apply CCAP within the context of the virtual team and empirically confirm the validity of the construct. Second, we examine the influence of CCAP within the virtual team, noting its beneficial effects of enhancing diversity-related outcomes. Third, this study examines two types of diversity (deeplevel and functional) and notes that CCAP is beneficial in enhancing effects related to functional-level diversity, yet CCAP does not significantly interact with deeplevel diversity. This finding suggests that CCAP is likely to be beneficial only when functional forms of diversity exist within the team; thus, extending insights for both researchers and managers.

The next two sections explain the theoretical framework and hypotheses. The methods and results are then reported. The final section discusses the main implications for the theory and practices. The study limitations and future research recommendations are also discussed.

\section{Literature Review}

\section{Virtual teams and integrated collaborative processes}

A requisite condition for the success of organisations is innovation. Innovation relates to the organisational capacity to participate and be involved in the introduction of new products, services, and ideas (Huang et al., 2011). The ability to innovate is among the most important dynamics that influence organisational success, and innovation is rapidly becoming increasingly vital to maintaining competitive edge in the global marketplace regardless of industry (Gorodnichenko et al., 2010).

In today's climate of globalisation, innovation frequently involves teams that are physically located across the globe. These teams must continually communicate and align with one another as they move forward on assigned projects and 


\section{F. S. Batarseh, J. M. Usher \& J. J. Daspit}

tasks. Given the difficulties associated with coordinating contributions from individuals who are not within close proximity, an efficient and integrated collaborative structure is critical to the completion of interdependent tasks and achievement of goals. The use of virtual teams is a common approach now pursued by many organisations seeking to bring together cross-functional teams or crossboundary skilled individuals (Lee-Kelley and Sankey, 2008; Pushpa and Mathew, 2012). Virtual teams allow organisations to meet the increasing demands to be responsive and agile in a competitive marketplace (Gressgård, 2011), and such teams have a flexible and configurable infrastructure can potentially conserves resources, resulting in increased productivity (Anderson and Carletta, 2007).

Virtual teams are becoming increasingly popular in the high-tech domain and are generally described as functionally diverse and geographically dispersed. Virtual teams enable geographically dispersed experts to be remotely connected to collaborate and innovate by using technology to share information and coordinate their efforts (Gressgård, 2011; Lipnack and Stamps, 2000). Technology experts no longer have to work in the same physical space but can engage in collaboration from any location around the world at any moment in time. Virtual teams are valuable in generating new knowledge through improved access to experts who can facilitate knowledge capture and expedite the exploration of creative and innovative solutions (Duarte et al., 2011; Zakaria et al., 2004). With the increased access to geographically dispersed individuals, virtual teams allow for the convergence of diverse knowledge perspectives, which may potentially enhance team project outcomes.

\section{Diversity}

Diversity is the degree to which noted differences exist among individuals within a team (van Knippenberg et al., 2004). Three primary types of diversity are commonly noted: surface-level, deep-level and functional-level (Bunderson and Sutcliffe, 2002; Harrison et al., 2002; Milliken and Martins, 1996). Surface-level diversity reflects largely observable differences such as age, sex, and race, while deep-level diversity consists of less easily identifiable differences in personal characteristics such as values, beliefs, and attitudes that are communicated through extended, personalized interaction and information gathering (Milliken and Martins, 1996). Functional-level diversity - also not easily observed - is the degree to which team members differ in knowledge, skills, information and expertise. The primary focus of this investigation relates to the role of deep-level and functional-level diversity within the virtual team. Although all forms of diversity have the potential to add value, we suggest that the value added by surface-level diversity is through the diverse knowledge resources rather than more observable 
characteristics. Thus, we employ a knowledge-based perspective in order to investigate how deep-level and functional-level diversity within the virtual team affect innovation-related outcomes. Furthermore, literature shows that surfacelevel diversity has less significant relationship with team processes, such as trust and knowledge sharing, than deep and functional-level diversity (Pinjani and Palvia, 2013). For this reason, we focus on investigating the role of deep- and functional-level diversity.

Two theoretical perspectives have emerged that note the positive and negative implications of diversity: the social categorisation perspective and the knowledge perspective. The social categorisation perspective argues that team members tend to create social categories (in-group and out-group) based on similarities and differences among them (Turner et al., 1987). In-group members tend to communicate more frequently and possess higher levels of trust more than the outgroup members. These natural tendencies occur given that in-group members share the same worldviews and shared perceptions (Moynihan et al., 2006). When diverse perspectives are introduced, preferences and biases tend to manifest if members do not have a shared sense of identity.

The second noted theoretical perspective relates to knowledge and suggests that diverse teams outperform homogeneous teams given that heterogeneous teams possess larger, more diverse pools of knowledge resources (Milliken and Martins, 1996) that include access to a broader range of relevant knowledge, skills, and abilities. These non-redundant resources provide an advantage to teams by enabling higher-quality decisions as well as more creative and innovative solutions (van Knippenberg et al., 2013). From this knowledge perspective, researchers therefore claim that team diversity has a positive effect on the team performance when diverse knowledge is managed via appropriate internal collaborations (Chae et al., 2015).

\section{Collaboration capability (CCAP)}

Collaboration is an integral contributor of success within teams. Refined collaboration capabilities support goal alignment, enhance frequent and open knowledge exchange, and create a willingness to share risks and rewards (Galunic and Rodan, 1997; Luca De and Atuahene-Gima, 2007). Underlying successful interpersonal collaboration is the capability to build and manage relationships based on trust, communication, and commitment, otherwise known as the CCAP of the team (Blomqvist and Levy, 2006).

Trust. Team trust is the level of confidence exercised among team members (Pinjani and Palvia, 2013). Trust is viewed by scholars as a fundamental lubricant for a social system, given its role in facilitating interpersonal interaction (Putnam, 
2000) and is colloquially described as the glue that binds virtual teams together (Lipnack and Stamps, 2000). Trust builds around the credibility and mutual goodwill of each team member, which engenders a general predictability of behaviour (Ulbrich et al., 2011). Mutual trust brings about a number of benefits in working relationships, such as open communication, better cooperation, and a high level of decision-making (McKnight et al., 1995). In the context of virtual teams, although developing trust often presents challenges given the limited in-person interaction (Rusman et al., 2010), trust becomes even more integral as members rely on one another to complete tasks successfully and on time. Henttonen and Blomqvist (2005) further argued that virtual teams are more likely to form trust in the presence of timely information sharing and sound communication responsiveness where communication is an essential component to building trust.

Communication. A large body of literature on team communication exists underscoring the importance of internal communication to the success of the team; however, an exploration into virtual collaboration is nascent (Badir et al., 2012; Piekkari and Tietze, 2011). Examining communication in this context is relevant given that virtual teams are affected by time zones, physical location, and cultural differences and thus more challenging to evaluate than collocated teams (Bjørn and Ngwenyama, 2009; Reed and Knight, 2010). Reed and Knight (2010) note that poor communication negatively impacts the sufficiency of knowledge transfer, posing risks for team performance. Bjørn and Ngwenyama (2009) also found that although virtual meetings have been identified to be crucial for the success of distributed teams, they could also lead to communication breakdowns under some circumstances such as language. Poor communication results in deterioration of the effectiveness of the team in building relationships and promoting efficient team coordination (Montoya et al., 2009) and is shown to be costly in terms of resources, frequently resulting in confusion and uncertainties that weaken the cohesion among the team members (Reed and Knight, 2010). Peters and Manz (2007) suggest that team members need to share their personal information by also sharing their visual images in order to build a sense of collaborative community, which will encourage deeper social interaction and relations within the virtual teams. Proper and frequent communication is a vital conduit through which valuable resources, such as knowledge, are exchanged.

Commitment. Meyer and Allen (1991) describe commitment as affective (desire to belong), normative (feeling obligation to stay), or continuance (awareness of cost of leaving). The type of commitment most beneficial to teams is affective commitment as indicated in a study which demonstrates that affective commitment exhibits a strong, positive correlation with team performance (Meyer and Herscovitch, 2002). Meyer and Herscovitch $(2002,129)$ explain commitment as "a force that binds an individual to a course of action of relevance to one or 
more targets". This psychological force has a large effect on the behaviour of the team member and the quality of collaboration (Chang et al., 2012). Members with strong affective commitment to the team are more apprehensive about the performance and the fate of the team, which, in turn, produces favorable collaborative behaviour (Kang et al., 2007). However, it is inherently more difficult to develop commitment in a virtual team where members rely entirely on technology and media to reinforce social bonds.

\section{Innovation}

Teams that are cohesive and share responsibilities are more likely to experience enhanced effectiveness and outcomes (Daspit et al., 2013). Among such outcomes, the collaborative team may experience an enhanced ability to innovate. In this study, innovation at the team level is defined as the intentional introduction and application of ideas, processes, products or procedures new to the team that are designed to significantly enhance the outcome of the team and the organization (West and Farr, 1990). The process of innovation entails various complex actions and behaviours that facilitate innovation activities (Forsman, 2009; Lawson and Samson, 2001; Van der valk et al., 2011). Because of the complexity and timeliness associated with innovation, the well-performing team is likely to have a refined CCAP, which supports the coordination of diverse and collective tasks. Innovation at the team level is inherently a social process that is facilitated by the CCAP. Therefore, we argue that CCAP nurtures innovation at the team level given that the structural and process components of CCAP enables the team to evaluate information, share new ideas, and develop innovative solutions (Blomqvist and Levy, 2006). The willingness of the virtual team members to share knowledge and new ideas is a an important factor in determining innovation success (Cabrera et al., 2006). Therefore, we argue that with well-developed CCAP, the team is better able to innovate.

\section{Moderating role of collaboration capability (CCAP)}

Researchers on team diversity have long argued that broadening the range of expertise of the team results in enhanced team innovation (Bantel and Susan, 1981). Accordingly, numerous studies find a relationship between diversity and innovation within a team (e.g., Gibson and Gibbs, 2006; Ostergaard et al., 2011). When deep-level diversity exists, members within a team have heterogeneous personalities, values, and attitudes (Harrison et al., 1998; Jackson and Joshi, 2004). The diversity of values and similar deep-level factors are shown to positively influence performance in global innovation teams, suggesting that such 


\section{F. S. Batarseh, J. M. Usher \& J. J. Daspit}

diversity provides the team with diverse perspectives beneficial for problemsolving and innovation (Winkler and Bouncken, 2011). Additionally, functionaldiversity in teams - demonstrated by the varied skills and expertise among members - provides access to a broad array of knowledge, and such knowledge resources are essential to innovation-oriented tasks. Studies of teams and organisations substantiate the significant relationship between functional-level diversity and innovation outcomes (Yap et al., 2005).

Although diverse teams are better able to respond to various types of change (Bowers et al., 2000) and competitive threats (Hambrick, 1996), virtual teams with deep and functional-level diversity may be unable to fully harvest the benefits of diverse knowledge resources if the trust, communication, and commitment among members is lacking. Blomqvist and Levy (2006) note that CCAP is formed by trust, communication, and commitment; that is, depending on the level of such factors, the CCAP within the team may promote or discourage the exchange of knowledge, which thereby effects innovation success. A virtual context also adds an additional layer of challenges in order to create functioning collaborative relations based on trust because electronically mediated interactions may weaken the collaborative ties between the virtual team members (Peters and Manz, 2007). Therefore, without a proper exchange of ideas and a variety of perspectives of how to solve innovation-related issues, achieving innovation-related success is hindered. Thus, collaboration is an integral factor if diverse teams are to secure advancement during innovation processes (Nissen et al., 2014).

Given the complex nature of the virtual team environment, we posit that the success of diverse virtual team innovation is strongly associated with CCAP as shown in Fig. 1. When virtual teams are characterised by deep-level diversity, a

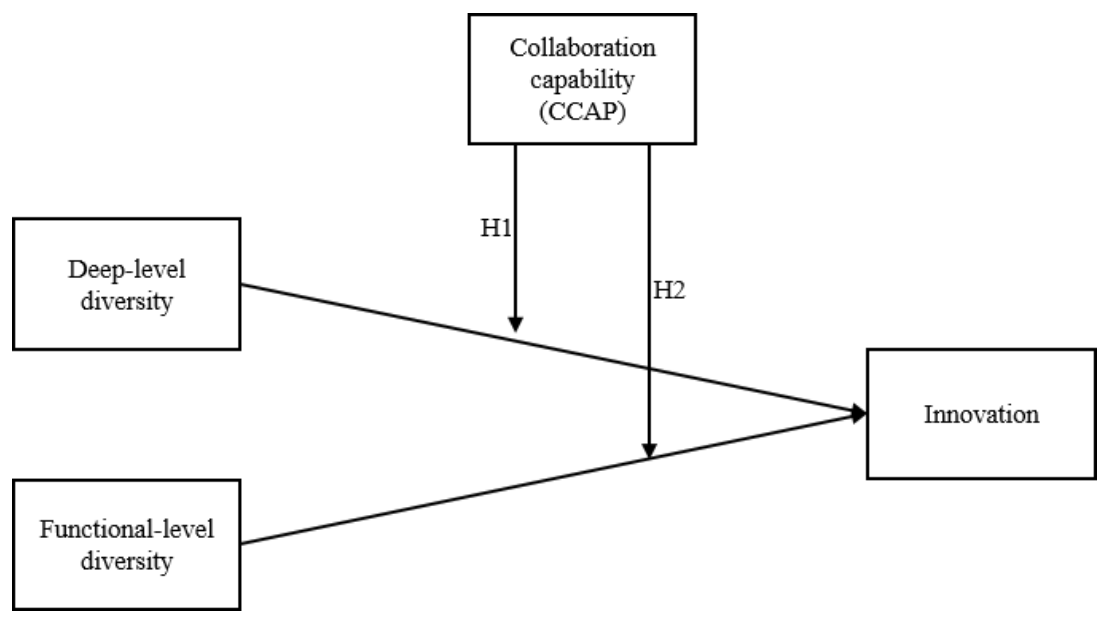

Fig. 1. The moderating role of CCAP on the relationship between virtual team diversity and innovation. 
variety of values, beliefs, and attitudes may undermine innovation efforts if team members are not guided by trust, communication, and commitment. Thus, when virtual teams with deep-level diversity have a refined CCAP, we suggest that members work together more collaboratively, thereby enhancing team innovation outcomes. Similarly, when virtual teams are composed of functional-level diversity, and a variety of knowledge, skills, and abilities exist among team members, we suggest that when collaboration among members is based on trust, communication, and commitment, innovation-related outcomes are enhanced.

Hypothesis 1. CCAP positively moderates the relationship between deep-level diversity and innovation, such that with higher levels deep-level diversity and CCAP, team innovation is higher.

Hypothesis 2. CCAP positively moderates the relationship between functionallevel diversity and innovation, such that with higher levels functional-level diversity and CCAP, team innovation is higher.

\section{Method}

\section{Sample}

A survey was conducted to validate the CCAP measure and test the hypothesised model. This approach is consistent with prior work that examined virtual teams and multi-dimensional construct validation. The sample for this study was collected from a global engineering department of a high-tech firm in Silicon Valley, California, which consists of 375 design and software engineers (42 teams) in multiple locations across Asia, Europe, and the United States. The respondents were asked to rate each statement of the composite survey based on their knowledge, experience, and understanding using a seven-point Likert scale. The survey was administered electronically and closed after four weeks. All data were collected in an anonymous form to protect anonymity and confidentiality of the respondents. The respondents' geographic locations were distributed across the globe, including various locations in the USA, Europe, China, Taiwan, and Singapore.

Ethical clearance and institutional permission from the participating company was obtained prior to conducting the research; however, the institution where this research was conducted did not permit the collection of specific demographic data citing the need to protect employee privacy. Employees in the global engineering department were asked to complete the questionnaire by a representative of the Human Resources department of the organisation. The survey was voluntary, and individual anonymity was guaranteed (citing the academic nature of the study). To enhance participation, participants were offered the opportunity to enter a raffle. 
A total of 166 respondents completed the questionnaire, yielding a response rate of $42.27 \%$. Of the 166 collected responses, 36 responses were incomplete and were removed from the final analysis. Therefore, a total of 130 responses were used for the analysis. Four of the 130 complete responses only had one piece of data missing; these values were then coded into SPSS as missing data.

Although specific demographic information was not collected from the respondents due to Human Resource department restrictions, data on educational background of the respondents was permitted. Of the participants responding to the questionnaire, $27 \%$ had a doctoral degree, 37\% had a Master's degree, 33\% had a Bachelor's degree, and 3\% had an Associate's degree.

\section{Measures}

Deep-level diversity. Following team diversity researchers (e.g., Pinjani and Palvia, 2013; Martins et al., 2003; Harrison et al., 2002), we used a nine-item scale adapted from Pinjani and Palvia (2013), which measures the perceived differences with respect to non-visible underlying personal characteristics such as values, beliefs, and attitudes.

Functional-level diversity. We used a three-item scale adapted from Pinjani and Palvia (2013) that measures the degree to which team members differ in their functional background and expertise.

CCAP. Blomqvist and Levy (2006) define CCAP as the ability to build and manage network relationships based on trust, communication, and commitment. Each dimension of CCAP was measured independently using existing validated scales from the literature. For team trust, we used a four-item measurement scale adapted from Pinjani and Palvia (2013). For team commitment, we used a fouritem scale adapted from Han and Harms (2010), and for team communication, we used the six-item scale adapted from Worley et al. (1999).

Innovation. We used a three-item scale adapted from Vera and Crossan (2005) that measures innovation at the team level.

Control variables. Previous research establishes that team size influences team performance (Haleblian and Finkelstein, 1993; Harrison et al., 2002) where, with an increase in team size, the psychological distance can increase (Pearce and Herbik, 2004). Thus, a control for team size is used given that CCAP is likely more difficult to develop in larger virtual teams, which is likely to affect team outcomes. Team tenure, measured as the length of the team's existence, is also likely to influence team outcomes (Barsade et al., 2000) and is thus used as a control variable. The longer the team members engage in interpersonal interaction, the greater the likelihood of CCAP. Finally, the degree of dispersion represents the extent to which a team is virtual (Staples and Webster, 2008). O'Leary and 
Cummings (2007) argue that team outcomes are differentially associated to the dimension of dispersion. In line with this recommendation, we control for the degree of dispersion by using two dispersion indices. First, an isolation index is used to measure the percent of team members with no other team members at their site. Low values of this index indicate low levels of isolation. Second, an imbalance index is used to assess the extent to which members are balanced across locations. This index is measured as: $\operatorname{StDev}\left(n_{1}, n_{2} \ldots n_{k}\right) / N$, where $k$ is the total number of sites represented in the team, $n_{i}$ is the number of team members from the $i$ th site, and $N$ is the total number of team members across all sites.

\section{Results}

\section{Assumption testing}

Prior to conducting the regression analyses for the hypotheses tests, the data were examined to evaluate the sample distribution. An exploration of the skewness and kurtosis values for all the variables were evaluated for normality. Cook's distance was also evaluated to examine outlying data. The maximum Cook's distance for the sample was less than 1 (0.47), which suggested no outlier cases impacted the model. The Durbin-Watson test value was less than 2 (1.93), an indication that the residuals were uncorrelated (Field, 2013). The variance inflation factor (VIF) and collinearity statistical tolerance were used to assess multicollinearity of the predictor variables. The results of these two test indicates that the VIF values for all predictors within the model are well below 10, with highest VIF of (1.07), and the tolerance values are also well above $0.20(0.94)$, which are indicators that no multicollinearity exists.

\section{Virtual team involvement}

The usage of virtual media by the virtual teams with the frequency responses for the various communication media is shown in Table 1. A high percent of the responses $(60.9 \%)$ show no face-to-face interaction or interactions that occur less than once a month, which is a consistent characteristic of virtual teams that rely on virtual communication technologies (Peters and Manz, 2007). This is in line with recent research that the virtual team members have less face-to-face interaction requiring that they rely on the use of different techniques for communication and forming relationships (Haines, 2014). A majority (91.9\%) of respondents use emails in their team communication on a weekly or daily basis. Emails are the most popular means of communication due to the ease of usage and the control of communication between the sender and the recipient (Harvey et al., 2004). Instant 
Table 1. Frequency of media usage.

\begin{tabular}{lcccccc}
\hline \multicolumn{7}{c}{ Media usage } \\
\hline Occurrence (\%) & F2F (\%) & Email (\%) & IM (\%) & TeleCalls (\%) & TeleConf (\%) & VideoConf (\%) \\
\hline Never & 36.7 & 5.6 & 23.8 & 11.2 & 17.8 & 58.9 \\
Less than & 24.2 & 1.6 & 4.0 & 5.6 & 4.7 & 18.5 \\
$\quad$ once a month & & & & & & \\
Once a month & 4.7 & 0.8 & 4.0 & 8.8 & 4.7 & 8.1 \\
Once a week & 6.3 & 2.4 & 5.6 & 30.4 & 34.9 & 10.5 \\
A few times a week & 14.8 & 29.0 & 32.5 & 32.8 & 27.9 & 0.8 \\
Daily & 13.3 & 60.5 & 30.2 & 11.2 & 10.1 & 3.2 \\
\hline
\end{tabular}

messaging is a popular application for communication with team members due to its ease of use and the instant communication response between the sender and the receiver. A total of $68.3 \%$ of responses used instant messaging on a weekly or daily basis. Telephone calls are also popular means of communication in virtual teams, with $74.4 \%$ of responses indicate telephone calls are used on weekly or daily bases. As well, only $14.5 \%$ of responses uses video conference communication on a weekly or daily basis.

\section{Measure validity and reliability}

We examined the reliability for each measure, and all measures had a Cronbach's $\alpha$ above the recommended level of 0.70 (Nunnally, 1978). Additionally, we examined the Corrected Item-Total Correlation to test if items in the questionnaire are inconsistent with the average of others. This step is performed prior to determining the factors that represent the underlying latent construct, and items are removed or further analysed if the item-to-corrected total correlation is 0.30 or below (De Vaus, 2008). After analysing the results (presented in Table 2), all the items met the appropriate specifications.

\section{Validation of the CCAP measure}

Blomqvist and Levy (2006) conceptually proposed CCAP (as a multi-dimensional construct consisting of trust, communication, and commitment) and argued that CCAP explains much of the success in knowledge creation and collaborative innovation. While Blomqvist and Levy (2006) did extensive theoretical development in support of CCAP and the associated dimensions, the contribution is of a conceptual nature. Thus, prior to empirically examining the hypotheses offered in 
Table 2. Reliabilities data item and construct level.

\begin{tabular}{|c|c|c|c|c|c|c|}
\hline \multirow[b]{2}{*}{ Scale } & \multirow[b]{2}{*}{ Item } & \multirow{2}{*}{$\frac{\text { Corrected }}{\text { Item-total }}$} & \multirow[b]{2}{*}{$\begin{array}{c}\text { Cronbach's } \\
\text { alpha if item } \\
\text { deleted }\end{array}$} & \multirow[b]{2}{*}{$\begin{array}{c}\text { Scale } \\
\text { Cronbach's } \\
\text { alpha }\end{array}$} & \multirow[b]{2}{*}{$\begin{array}{l}\text { Composite } \\
\text { reliability }\end{array}$} & \multirow[b]{2}{*}{$\begin{array}{l}\text { Average } \\
\text { variance } \\
\text { explained }\end{array}$} \\
\hline & & & & & & \\
\hline \multirow{3}{*}{$\begin{array}{c}\text { Functional-level } \\
\text { diversity }\end{array}$} & DiversityFunc 1 & 0.56 & 0.76 & 0.78 & 0.76 & 0.7 \\
\hline & DiversityFunc 2 & 0.6 & 0.72 & & & \\
\hline & DiversityFunc 3 & 0.69 & 0.62 & & & \\
\hline \multirow{9}{*}{$\begin{array}{l}\text { Deep-level } \\
\text { Diversity }\end{array}$} & DiversityDeep 1 & 0.42 & 0.82 & 0.83 & 0.83 & 0.62 \\
\hline & DiversityDeep 2 & 0.55 & 0.8 & & & \\
\hline & DiversityDeep 3 & 0.63 & 0.79 & & & \\
\hline & DiversityDeep 4 & 0.66 & 0.79 & & & \\
\hline & DiversityDeep 5 & 0.53 & 0.81 & & & \\
\hline & DiversityDeep 6 & 0.43 & 0.82 & & & \\
\hline & DiversityDeep 7 & 0.62 & 0.8 & & & \\
\hline & DiversityDeep 8 & 0.42 & 0.82 & & & \\
\hline & DiversityDeep 9 & 0.51 & 0.81 & & & \\
\hline \multirow[t]{6}{*}{ Communication } & CCAP_Comm 1 & 0.64 & 0.86 & 0.88 & 0.87 & 0.63 \\
\hline & CCAP_Comm 2 & 0.61 & 0.87 & & & \\
\hline & CCAP_Comm 3 & 0.67 & 0.86 & & & \\
\hline & CCAP_Comm 4 & 0.72 & 0.85 & & & \\
\hline & CCAP_Comm 5 & 0.85 & 0.83 & & & \\
\hline & CCAP_Comm 6 & 0.62 & 0.87 & & & \\
\hline \multirow[t]{4}{*}{ Commitment } & CCAP_Commit 1 & 0.73 & 0.91 & 0.91 & 0.9 & 0.79 \\
\hline & CCAP_Commit 2 & 0.85 & 0.87 & & & \\
\hline & CCAP_Commit 3 & 0.8 & 0.89 & & & \\
\hline & CCAP_Commit 4 & 0.82 & 0.88 & & & \\
\hline \multirow[t]{4}{*}{ Trust } & CCAP_Trust 1 & 0.71 & 0.83 & 0.86 & 0.86 & 0.73 \\
\hline & CCAP_Trust 2 & 0.69 & 0.83 & & & \\
\hline & CCAP_Trust 3 & 0.68 & 0.84 & & & \\
\hline & CCAP_Trust 4 & 0.78 & 0.8 & & & \\
\hline \multirow[t]{3}{*}{ Innovation } & Team_Innovation 1 & 0.78 & 0.85 & 0.89 & 0.87 & 0.83 \\
\hline & Team_Innovation 2 & 0.79 & 0.85 & & & \\
\hline & Team_Innovation 3 & 0.8 & 0.83 & & & \\
\hline
\end{tabular}

this study, we proceed by empirically validating the measure of CCAP as proposed by Blomqvist and Levy (2006). After establishing the measure, we then investigate the moderating role of CCAP as posited in the previously offered hypotheses.

Confirmatory analysis. A confirmatory factor analysis (CFA) was conducted to determine the ability of a predefined theoretical model to fit an observed set of empirical data (Brown, 2006). Blomqvist and Levy (2006) describe CCAP as a socially complex phenomenon composed of three interrelated dimensions (trust, 
Table 3. Summary of fit indices.

\begin{tabular}{lcccccccc}
\hline CFA & $\chi 2$ & $d f$ & $\chi^{2} / d f<2$ & CFI $>0.90$ & NFI $>0.90$ & IFI $>0.90$ & RMSEA $<0.08$ & SMSR $<0.08$ \\
\hline $\begin{array}{l}\text { Three } \\
\text { dimensional } \\
\text { CCAP model }\end{array}$ & 98.74 & 63.0 & 1.56 & 0.970 & 0.924 & 0.971 & 0.06 & 0.06 \\
\hline
\end{tabular}

communication, and commitment). The primary purpose of this CFA model is to explain and analyse the interrelated relationships simultaneously between the set of first-order latent variables (trust, communication, and commitment) and a second-order latent variable (CCAP). The CFA technique allows analysing models with latent variables, which yields correlations and regression coefficients among the latent construct (Brown, 2006). Fit statistics are used to test the CFA model for an overall goodness of fit, and the fit indices are used to evaluate the residuals that result from fitting a model to the empirical data (Brown, 2006). The overall fit of the CFA measurement model in this study was evaluated using maximum likelihood structural equation modelling (SEM) with the IBM AMOS version 22 software, and the results examined for the following indices that are recommend by Brown (2006).

Table 3 shows a summary of fit indices for the hypothesised model. The proposed second-order model demonstrated good fit $\left(\chi^{2} / d f=1.56, \mathrm{CFI}=0.97\right.$, $\mathrm{IFI}=0.97$, RMSEA $=0.06$ and SMSR $=0.06$ ). The values of CFI greater than 0.90 , and a ratio of chi-square to the degrees of freedom less than 2 , suggest the model is of acceptable fit (Kline, 2005). Based on the result of the CFA, the theorised model of CCAP is considered to be a valid representation of the data.

Convergent validity. Convergent validity is the degree to which the items in a factor agree in their measurement of that factor. Convergent validity is specified by significant factor loadings of each of the measures on an appropriate scale (Anderson and Gerbing, 1998). Hair Jr et al. (2006) recommend that all factor loadings should have a value greater than 0.50 to be statistically significant. As shown in Table 4, all factor loadings for the observed variables were statistically significant at $p<0.05$. These data provide supporting evidence of the convergent validity of the items, which effectively measure the same underlying construct of CCAP.

Discriminant validity. To test and evaluate the discriminant validity of the CCAP construct, discriminant validity among the CCAP dimensions was tested in two ways. First, Anderson and Gerbing (1998) suggest modifying the unconstrained free model with the correlations among the construct dimensions set to 1.0 (constrained model), and then compare goodness of fit statistics of the constrained with the unconstrained model. Second, the CFA was modified by comparing the hypothesised CCAP model with a single-dimension model that combines 
Table 4. Factor loadings for constructs and items.

\begin{tabular}{lcc}
\hline Construct & Item & Factor loading* \\
\hline Communication & CCAP_Comm 1 & 0.732 \\
& CCAP_Comm 2 & 0.651 \\
& CCAP_Comm 3 & 0.725 \\
& CCAP_Comm 4 & 0.764 \\
& CCAP_Comm 5 & 0.924 \\
Commitment & CCAP_Comm 6 & 0.644 \\
& CCAP_Commit 1 & 0.763 \\
& CCAP_Commit 2 & 0.895 \\
Trust & CCAP_Commit 3 & 0.843 \\
& CCAP_Commit 4 & 0.894 \\
& CCAP_Trust 1 & 0.757 \\
& CCAP_Trust 2 & 0.705 \\
& CCAP_Trust 3 & 0.832 \\
& CCAP_Trust 4 & 0.881 \\
\hline
\end{tabular}

Note: *Significant at the 0.05 level.

communication, trust, and commitment into one factor. If the construct shows proper discriminant validity, then the single-dimension model and the unconstrained free model should show less appropriate fit.

The fit statistics for these models are shown in Table 5, the results reveal that the theorised three-dimensional CCAP model has a better fit than both the onedimension and constrained models. Compared to the unconstrained three-dimension model (M1), the data suggest that the constrained model and the one-dimension model consistently fit the data significantly worse than the unconstrained model, providing support for the discriminant validity of each subscale of the CCAP. This result confirms discriminant validity and provides support that CCAP is a higherorder factor with the three dimensions (trust, communication, and commitment).

Table 5. Discriminant validity test.

\begin{tabular}{lcccccccc}
\hline CFA & $\chi 2$ & $d f$ & $\chi 2 / d f<2.0$ & $>0.90$ & $>0.90$ & $>0.90$ & $\begin{array}{c}\text { CFI } \\
<0.08\end{array}$ & $\begin{array}{c}\text { NFI } \\
<0.08\end{array}$ \\
\hline $\begin{array}{l}\text { M1.three } \\
\text { dimensional model }\end{array}$ & 98.74 & 63.0 & 1.56 & 0.970 & 0.924 & 0.971 & 0.06 & 0.06 \\
$\begin{array}{l}\text { M2.three } \\
\text { dimensional } \\
\text { constrained model }\end{array}$ & 109.6 & 66.0 & 1.662 & 0.964 & 0.916 & 0.965 & 0.065 & 0.065 \\
$\begin{array}{l}\text { M3.one } \\
\text { dimensional model }\end{array}$ & 208.9 & 66.0 & 3.16 & 0.88 & 0.839 & 0.884 & 0.130 & 0.085 \\
\hline
\end{tabular}


Table 6. Means, SD and correlations.

\begin{tabular}{lrrrrrrrrr}
\hline & Mean & SD & 1 & 2 & 3 & 4 & 5 & 6 & 7 \\
\hline (1) ImbalanceIndex & 0.22 & 0.15 & & & & & & & \\
(2) TeamTenure & 6.01 & 5.81 & 0.04 & & & & & & \\
(3) IsolationIndex & 0.16 & 0.08 & -0.05 & -0.09 & & & & & \\
(4) TeamSize & 7.28 & 2.04 & -0.15 & 0.13 & $-0.20^{*}$ & & & & \\
(5) Deep-level & 2.72 & 1.18 & $-0.20^{*}$ & 0.04 & $-0.020^{*}$ & -0.02 & & & \\
$\quad$ diversity & & & & & & & & & \\
(6) Functional-level & 3.86 & 1.59 & -0.06 & -0.08 & -0.02 & -0.01 & $0.19^{*}$ & & \\
$\quad$ diversity & & & & & & & & & \\
(7) CCAP & 15.06 & 3.07 & 0.09 & $-0.15^{*}$ & $0.17^{*}$ & $-0.17^{*}$ & $-0.50^{*}$ & -0.05 & \\
(8) Innovation & 5.09 & 0.97 & 0.13 & -0.14 & $0.19^{*}$ & -0.13 & $-0.031^{* *}$ & $0.24^{* *}$ & $0.55^{* *}$ \\
\hline
\end{tabular}

Notes: * Correlation is significant at the 0.05 level (1-tailed).

** Correlation is significant at the 0.01 level (1-tailed).

Nomological Validity. Nomological validity inspects the predictive ability of the nomological network of variable (Bhattacherjee, 2002). Investigating the nomological network surrounding a construct and the testing of predictions in that theoretical network guards against the inflation of internal psychometric properties (Bagozzi, 1981). To examine nomological validity, the correlation analysis was used to evaluate if positive correlations exist for the relationships expected to be positive. Functional-level diversity was expected to have a positive relationship with innovation since functional-level diversity provides access to a broad array of knowledge and such knowledge resources are essential to innovation-oriented tasks (Yap et al., 2005). As shown in Table 6, functional-level diversity is positively correlated with innovation $(r=0.24, p<0.01)$. Further, CCAP was expected to be positively related to innovation and is positively correlated $(r=0.55, p<0.01)$. Similar examinations of other constructs indicate that nomological validity holds.

\section{Hypothesis Testing}

A hierarchical moderated regression analysis (HMRA) approach, as described by Baron and Kenny (1986), is used to examine the moderating influence of CCAP. The moderation hypotheses are tested individually by using a sequence of regressions for each intermediate analysis as well as for the final dependent analysis. Table 6 shows the means, standard deviations (SD), and the correlation matrix for study variables. The results of the hierarchical regression model are presented in Table 7. In step 1, control variables were entered into the regression model. In step 2, the main effects for deep-level diversity and CCAP were entered 
Table 7. Moderation analysis for hypothesis 1 .

\begin{tabular}{lrrrrr}
\hline DV: Innovation & $\beta$ & $F($ model $)$ & $R$ & $R^{2}$ & $\Delta R^{2}$ \\
\hline Model 1: control variables & & & & & \\
Imbalance index & -0.001 & 0.503 & 0.149 & 0.022 & 0.022 \\
Team tenure & -0.031 & & & & \\
Isolation index & 0.134 & & & & \\
Team size & -0.102 & & & & \\
Model 2: main effects & & & & & \\
Deep-level diversity & $-0.172^{* *}$ & $4.38^{* *}$ & 0.482 & 0.232 & 0.210 \\
CCAP & $0.055^{* *}$ & & & & \\
Model 3: Interactions & & & & & \\
Deep level diversity X CCAP & -0.011 & 3.74 & 0.483 & 0.233 & 0.001 \\
\hline
\end{tabular}

Notes: ** Significant at $p<0.01$, Unstandardised $\beta$ reported, $n=130$.

into the regression model, and in the third step, the interaction effect for CCAP and deep-level diversity was entered into the regression equation.

Results of the HRM revealed that the control variables in Model 1 of Table 7 are not statistically significant $(F=0.50, p>0.05)$. In Model 2 , the two main effect variables (deep-level diversity, CCAP) were examined and are significant $(p<0.05)$ and explain $21 \%$ of the variance in the innovation output. In Model 3, the interaction term (deep-level diversity X CCAP) was examined, however, the results of the interaction term $(\beta=-0.01, p>0.05)$ did not demonstrate significance. Based on this data, moderation is not supported given the lack of significance. Therefore, Hypothesis 1 is not supported.

The result of the hierarchical regression model for Hypothesis 2 is presented in Table 8 . In step 1, control variables were entered into the regression equation. In

Table 8. Moderation analysis for hypothesis 2 .

\begin{tabular}{lrrrrr}
\hline DV: Innovation & $\beta$ & $F$ (model) & $R$ & $R^{2}$ & $\Delta R^{2}$ \\
\hline Model 1: control variables & & & & & \\
Imbalance index & 0.00 & 0.503 & 0.149 & 0.02 & 0.02 \\
Team tenure & -0.03 & & & & \\
Isolation index & 0.13 & & & & \\
Team size & -0.10 & & & & \\
Model 2: main effects & & & & & \\
Functional-level diversity & $0.09^{* *}$ & $4.8^{* *}$ & 0.50 & 0.25 & 0.23 \\
CCAP & $0.16^{* *}$ & & & & \\
Model 3: interactions & & & & & \\
Func level diversity $X$ CCAP & $0.05^{* *}$ & $5.75^{* *}$ & 0.57 & 0.32 & 0.07 \\
\hline
\end{tabular}

Notes: $* *$ Significant at $p<0.01$, Unstandardised $\beta$ reported, $n=130$. 
step 2, the main effects for functional-level diversity and CCAP were entered into the regression model, and in the third step, the interaction effect for CCAP and functional-level diversity was entered into the regression equation.

Results of the HRM revealed that the control variables in Model 1 of Table 8 are not statistically significant $(F=0.50, p>0.05)$. In Model 2 , the two main effect variables (functional-level diversity, CCAP) were examined and are positive and significant $(p<0.05)$ explaining $22.7 \%$ of the variance in the innovation output. In Model 3, the interaction term (functional-level diversity X CCAP) was examined, and the result of the interaction term $(\beta=0.05, p<0.01)$ is positive and significant. Based on these results, Hypothesis 2 is supported.

\section{Discussion and Implications}

Given the growing presence of virtual teams in organisations, we investigate how some virtual teams yield more innovation success than others. Specifically, we examine the role of CCAP in facilitating the diversity-related benefits gained from virtual teams. Our findings not demonstrate a valid measurement of CCAP but also highlight that CCAP is effective in enhancing some forms of diversity but not all. The insights gained offer numerous contributions to extant literature.

The first contribution of this research is the empirical validation of CCAP as a higher-order factor with three dimensions (trust, communication, and commitment). Reliability indicators, factor loadings, and convergent validity revealed that all the indicators are related to the underlying constructs they were designed to measure. Discriminant validity of the construct demonstrated that the three distinctive dimensions exist in the CCAP model. The evidence of reliability and validity provides support for the CCAP model as well as information about the usefulness of the CCAP construct. This insight represents a step toward the validation of the CCAP conceptualisation that was first proposed by Blomqvist and Levy (2006) within a virtual context by offering a psychometrically valid scale for the study of CCAP. Our findings suggest that the three manifestations of CCAP dimensions of trust, communication, and commitment are valid indicators of an underlying CCAP within a virtual team. This empirical analysis allows for more fine-grained research on CCAP and the ability to analyse CCAP dimensions in concert with one another, supporting further research opportunities in this field.

Following the empirical validation of the CCAP construct, the hypotheses were examined to determine the influence of CCAP on the relationship between team diversity (deep-level and functional-level diversity) and team innovation. The results indicated that there is no moderation effect of CCAP on the relationship between deep-level diversity and team innovation. It was evident from the data that a high percent $(91.9 \%)$ used emails as the preferred technological 
medium for communication and interaction with each other and other team members $(60 \%)$ had no face-to-face interaction. The email dependency and the lack of face-to-face interaction may be a strong contributor to the lack of moderation and interaction between deep-level diversity and CCAP. This lack of interaction reasoning due to high email dependency can be further justified based on the arguments by Harrison et al. (1998) that team members detect and identify the personalities and the non-visible underlying characteristics of their teammates through interactions and observations of non-verbal behaviour.

Given the possibility of media richness affecting the insignificant finding in Hypothesis 1, we conducted an additional analysis wherein we split the sample into two groups (high and low media richness users) and re-examined the moderating effect of CCAP in both groups. The results remains consistent: the moderating effect of CCAP on the relationship between deep-level diversity and innovation remains insignificant despite the level of media richness. Thus, it may be possible that deeplevel traits are not necessarily factors that are exchanged among virtual teammates since such traits are not easily detected and exchanged in a virtual environment. To do so, an extended period of time is likely necessary for these perceived differences to surface and be significant contributors in the behaviour of the team.

On the other hand, the moderation effect of CCAP on the relationship between functional-level diversity and team innovation was determined to be statistically significant. This is a noted finding of this research given that a primary purpose for forming virtual teams is to pool core competencies from experts of various technical and functional backgrounds (Hertel et al., 2006). This research finds that CCAP plays a significant moderating role in the virtual team environment and in relational building that facilitates higher levels of team innovation. Highly collaborative virtual team members use their complementary and collective knowledge to achieve higher levels of innovation. In virtual teams that depict high functionallevel diversity, having CCAP is likely to enhance innovation outcomes.

The findings of this research have valuable implications for how researchers and managers address the benefits of functional-level diversity and the challenges of deep-level diversity in virtual teams. The results of this investigation call for more detailed attention to deep-level diversity in order to examine how to offset the potentially negative effects on the team's collaboration process. Although this finding was not significant, it is a potentially important insight of which managers should be aware. Offsetting the negative effect may be done through training for team members to facilitate collaboration building and to detect and resolve conflicts immediately as they arise. Conflict in virtual teams negatively impact team member perceptions and the desire to remain with the team (Tekleab and Quigley, 2014) and, thus, should be addressed immediately. Virtual team managers can achieve higher innovative performance through creating an environment of collaboration 
in terms of trust, communication, and commitment among the team members. A highly collaborative environment in a diverse virtual team can be a key activator of knowledge creation which is a critical enabler for innovation (Blomqvist and Levy, 2006; Esterhuizen et al., 2012).

Although not explicitly hypothesised in this study, an additional insight gained relates to the positive and significant relationship between CCAP and innovation. This significant relationship underscores the importance of trust, collaboration, and commitment in driving team success with respect to innovation. Managers interested in enhancing innovation-related outcomes in virtual teams are encouraged to closely consider making strategic investments in efforts to enhance the overall CCAP of the team.

This study also notes that team innovation in global and virtual environment is complex, and leaders have an ongoing challenge of improving collaboration infrastructure among virtual teams. This can be done by building trust among team members, providing the appropriate tools of communication, and continuing to motivate team members to share knowledge and resolve communication issues. Team leaders are also encouraged to ensure commitment to the task and common goals, which align the team with desired performance outcomes.

Virtual team leaders have also the responsibility to monitor the team's CCAP. Virtual teams tasked with technology development and innovation are intended to collaborate with each other rigorously. Therefore, our CCAP model and framework will aid the virtual team leaders in assessing and monitoring their team's CCAP. By monitoring this capability, leaders may proactively take the necessary action to enhance collaboration among virtual team members for improved innovation performance. This model also demonstrates a practical and comprehensive way to measure team's CCAP. A key aspect of this scale is that managers can use the CCAP model as a comparative measure between teams by measuring and managing virtual team collaboration as an important competitive advantage in their firms.

\section{Limitations and future research}

Although the findings of this investigation contribute to the advancement of virtual team research, the findings should be interpreted with respect to the study's limitations. First, the sample was drawn from a single organisation, which limits the generalisation of the findings. Future researchers are encouraged to examine CCAP in alternate contexts and industries to further validate the measurement and noted relationships with team phenomena.

Second, the non-probability sampling approach used in this study poses a potential limitation. Random sampling was not an option since this study involved a specific sample within one organisation. The organisation in which the study was conducted 
did not permit the collection of respondent age, gender, and similar demographic data. Thus, future researchers are encouraged to explore the demographic contexts in which CCAP is optimal and under what conditions CCAP is restricted.

Third, another limitation is potential common method variance (CMV). Podsakoff et al. (2003) indicate that survey-based research has the possibility of having a CMV bias in situations where a study relies on self-reported measures. In this study, CMV could arise given one respondent reporting for all observed measures. We attempted to minimize the bias by assuring the participants that the survey would be anonymous and encouraging honesty in responses. Researchers that have studied this methodological issue have concluded that even if CMV bias exists in the observed correlations, it is not necessarily sufficient to challenge the theoretical interoperation of the relationships (Doty and Glick, 1998). They further indicated that although CMV bias should be avoided to the extent that this is possible, it is not likely to be large enough to invalidate the theoretical interpretations and research conclusions (Doty and Glick, 1998). The presence of CMV was evaluated in this study by using Harman's single-factor method (Podsakoff et al., 2003). Through the use of this method, no single factor emerged accounting for more than $50 \%$ of the overall variance suggesting that $\mathrm{CMV}$ did not impose a notable effect.

Fourth, to limit the influence of non-response bias, the sample was divided into two groups consisting of early and late respondents (Armstrong and Overton, 1977) at the date midpoint between the first and the last respondent. Differences in the groups (early respondents and late respondents) were analysed for all the variables. Statistical significance was estimated, and no significant differences existed suggesting nonresponse bias did not affect the results.

Last, this study used the correlation method design, which requires caution when interpreting correlations and relationships. Casual inferences must be treated with caution when using these types of correlation studies. Although the results are consistent with prior research and with our hypothesised model, extending our casual inference should be taken with caution.

Furthermore, this study suggests a number of implications for future research, many of which were previously noted. Additionally, future researchers are encouraged to extend the current study to determine whether similar results and relationships are achieved in various industries that rely on virtual teams such as software companies. Testing this model in different work environments would address its generalizability. Another challenge for future research is to confirm our finding with respect to Hypothesis 1 that CCAP does not moderate the relationship between deep-level diversity and innovation. Future research is encouraged to track the relationship between CCAP and deep-level diversity in a rich media environment and also in the different lengths of the time periods of collaboration in order validate Hypothesis 1. In addition, identification of factors that facilitate 
deep-level diversity on team performance could be conducted in a future study by using different models and methods. Future research should attempt to disentangle the effects of deep-level diversity on virtual teams. For example, how familiar do virtual team members need to be with one another in order to outweigh the negative effect of deep-level diversity?

\section{Conclusion}

This study addresses issues important to globally distributed virtual teams. The purpose of this investigation is to understand CCAP in virtual teams and to demonstrate how team diversity affects team innovation. This study offers an empirical validation of CCAP, noting that CCAP consists of three primary dimensions: trust, communication, and commitment. Additionally, the effects of CCAP within the context of the virtual team are examined.

The results of the study did not support the expectation that CCAP moderates the relationship between deep-level diversity and innovation. However, CCAP was shown to be significantly influential in virtual teams with function-level diversity. While the common wisdom in organisations assumes diversity is beneficial to teams because diversity brings various perspectives to the table to solve complex problems, this study demonstrates that CCAP has a significant role in virtual teams where functional-level diversity exists. Through the validation of CCAP and the findings of how CCAP relates to diversity and innovation, numerous insights are gained and opportunities for future research are noted. Further examinations into the internal dynamics of the virtual team are likely to offered continued insights into how such teams can be designed for optimal outcomes.

\section{Appendix}

Deep-level diversity (adapted from Pinjani and Palvia (2013)

(1) Members of the team are similar in terms of their personal values.

(2) Members of the team are similar in terms of their personalities.

(3) Members of the team are similar in terms of their attitudes towards the project.

(4) Members of the team are similar in terms of their attitudes towards the project goals.

(5) The well-being of fellow team members is important to members of the team.

(6) It is important for members to maintain harmony within the team.

(7) Members of the team like sharing information with my fellow team members.

(8) It is important for members to consult other team members before making a decision. 
(9) Members help fellow team members in their time of difficulty.

Functional-level diversity (adapted from Pinjani and Palvia (2013)

(1) Members of the team are similar in terms of their functional expertise.

(2) Members of the team are similar in terms of their educational background.

(3) Members of the team are similar in terms of their length of experience.

\section{CCAP}

Trust (adapted from Pinjani and Palvia, 2013)

(1) Team members can rely on fellow team members.

(2) Members of the team are very trustworthy.

(3) Team members are friendly towards each other.

(4) Team members in this team are considerate of other's feelings.

Commitment (adapted from Han and Harms, 2010)

(1) Team members feel a strong sense of belonging to their team.

(2) Team members feel as if the team's problems are their own.

(3) Team members feel emotionally attached to their team.

(4) Team members feel like part of the family in their team.

Communication (adapted from Worley et al., 1999)

(1) If we have a decision to make, everyone is involved in making it.

(2) Team members are afraid to express their real views.

(3) We tell each other the way we are feeling.

(4) Within the team, everyone's opinion gets listened to.

(5) Within the team, people say what they really mean.

(6) Team members are encouraged to express our concerns openly.

Innovation (adapted from Vera and Crossan, 2005)

(1) The team is highly innovative.

(2) The team is fast in adopting new innovative solutions.

(3) The team frequently introduces new innovative solutions.

\section{References}

Alavi, M and A Tiwana (2002). A Knowledge Integration in Virtual Teams: The Potential Role of KMS. Journal of the American Society for Information Science and Technology, 53(12), 1029-1037. 
Anderson, MR and JB Carletta (2007). Virtual team meetings: An analysis of communication and context. Computers in Human Behavior, 23(5), 2558-2580.

Anderson, J and D Gerbing (1998). Structural equation modeling in practice: A review and recommendation two step approach. Psycollogical Bulletin, 103, 411-423.

Armstrong, JS and TS Overton (1977). Estimating Nonresponse Bias in Mail Surveys. Journal of Marketing Research, 14, 396-402.

Badir, YF, B Büchel and CL Tucci (2012). A conceptual framework of the impact of NPD project team and leader empowerment on communication and performance: An alliance case context. International Journal of Project Management, 30(8), 914-926.

Bagozzi, R (1981). Causal modeling: A general method for developing and testing theories in consumer research. Advances in Consumer Research, 08, 195-202.

Bantel, K and J Susan (1981). Top management and innovations in banking: Does the composition of the top team make a difference? Strategic Management Journal, 10, 107-124.

Baron, R and D Kenny (1986). The moderator-mediator variable distinction in social psychological research: Conceptual, strategic, and statistical considerations. Journal of Pe n nality and Social Psychology, 51(6), 1173-1182.

Barsade, SG, AJ Ward, JDF Turner and JA Sonnenfeld (2000). To your heart's content: A model of affective diversity in top management teams. Administrative Science Quarterly, 45(4), 802-836.

Bhattacherjee, A. (2002). Individual trust in online firms: Scale development and initial test. Journal of Management Information Systems, 19(1), 211-241.

Bjørn, P and O Ngwenyama (2009). Virtual team collaboration: Building shared meaning, resolving breakdowns and creating translucence. Information Systems Journal, 19(3), 227-253.

Blomqvist, K and J Levy (2006). Collaboration capability — a focal concept in knowledge creation and collaborative innovation in networks. International Journal of Management Concepts and Philosophy, 2(1), 31-48.

Bowers, CA, JA Pharmer and E Salas (2000). When member homogeneity is needed in work teams: A meta-analysis. Small Group Research, 31(3), 305-327.

Brown, T (2006). Confirmatory Factor Analysis for Applied Research, First Edition. The Builford Press.

Bunderson, JS and KM Sutcliffe (2002). Comparing alternative conceptualizations of functional diversity in management teams: Process and performance effects. Academy of Management Journal, 45(5), 875-893.

Cabrera, Á, WC Collins and JF Salgado, (2006). Determinants of individual engagement in knowledge sharing. The International Journal of Human Resource Management, 17(2), 245-264.

Carmel, E and P Tjia (2005). Offshoring Information Technology: Sourcing and Outsourcing to a Global Workforce. UK: Cambridge University Press.

Chae, SW, YW Seo and KC Lee (2015). Task difficulty and team diversity on team creativity: Multi-agent simulation approach. Computers in Human Behavior, 42, 83-92. 
Chang, Y-C, H-T Chang, H-R, Chi, M-H, Chen and L-L Deng (2012). How do established firms improve radical innovation performance? The organizational capabilities view. Technovation, 32(7-8), 441-451.

Daspit, J, Justice Tillman, C, Boyd, NG and V Mckee (2013). Cross-functional team effectiveness: An examination of internal team environment, shared leadership, and cohension influences. Team Performance Management: An International Journal, 19(1/2), 34-56.

De Vaus, D (2008). Analyzing Social Science Data. California: Sage Publication Ltd.

Doty, DH and WH Glick (1998). Common methods bias: Does common methods variance really bias results? Organizational Research Methods, 1(4), 374-406.

Duarte, L, S Deborah and N Tennant (2011). Mastering Virtual Teams: Strategies, Tools, and Techniques That Succeed, 3rd Edition, New York: John Wiley and Sons, Ltd.

Esterhuizen, D, CSL Schutte and ASA du Toit (2012). Knowledge creation processes as critical enablers for innovation. International Journal of Information Management, 32(4), 354-364.

Ferrazzi, K. (2014). Getting virtual teams right. Harvard Business Review, Press, December 2014 issue.

Field, A (2013). Discovering statistics using IBMSPSS statistics. (T Oaks, Ed.) (4th ed.). Sage.

Forsman, H (2009). Improving innovation capabilities of small enterprises: Cluster strategy as a tool. International Journal of Innovation Management, 13(2), 221243.

Galunic, C and S Rodan (1997). Resource Recombinations in the Firm: Knowledge Structures and the Potential for Schumpeterian Innovation. France: INSEAD.

Gartner, I (2011). Techniques and tools for Project Collaboration. Available at: http:// www.gartner.com/id=1714619.

Gibson, CB and JL Gibbs (2006). Unpacking the concept of virtuality: The effects of geographic dispersion, electronic dependence, dynamic structure, and national diversity on team innovation. Administrative Science Quarterly, 51(3), 451-495.

Goerzen, A and PW Beamish (2005). The effect of alliance network diversity on multinational enterprise performance. Strategic Management Journal, 26(4), 333-354.

Gorodnichenko, Y, J Svejnar and K Terrell (2010). Globalization and innovation in emerging markets. American Economic Journal: Macroeconomics, 2(2), 194-226.

Gressgård, LJ (2011). Virtual team collaboration and innovation in organizations. Team Performance Management, 17(1), 102-119.

Griffith, TL, JE Sawyer and MA Neale (2003). Virtualness and knowledge in teams: Managing the love triangle of organizations, individuals, and information technology. MIS Quarterly, 27(2), 265-287.

Haines, R (2014). Group development in virtual teams: An experimental reexamination. Computers in Human Behavior, 39(0), 213-222.

Hair, JrJ, R Anderson, R Tatham and W Black (2006). Multivariate Data Analysis, 6th Edition: With Readings. Upper Saddle River, NJ, USA: Prentice-Hall, Inc. 
Haleblian, J and S Finkelstein (1993). Top management team size, CEO dominance, and firm performance: The moderating roles of environmental turbulence and discretion. Academy of Management Journal, 36(4), 844-863.

Hambrick, DC (1996). The influence of top management team heterogeneity on firms' competitive moves. Administrative Science Quarterly, 41, 659-684.

Han, GH and PD Harms (2010). Team identification, trust and conflict: A mediation model. International Journal of Conflict Management, 21(1), 20-43.

Harrison, D, H Price, J Gavin and A Florey (2002). Time, teams, and task performance: Changing effects of surface- and deep-level diversity on group functioning. Academy of Management Journal, 45(5), 1029-1045.

Harrison, D, K Price and M Bell (1998). Beyond relational demography: Time and the effects of surface- and deep-level diversity on work group cohesion. Academy Management Journal, 41(1), 98-107.

Harvey, M, MM Novicevic and G Garrison (2004). Challenges to staffing global virtual teams. Human Resource Management Review, 14(3), 275-294.

Henttonen, $\mathrm{K}$ and $\mathrm{K}$ Blomqvist (2005). Managing distance in a global virtual team: the evolution of trust through technology-mediated relational communication. Strategic Change, 14(2), 107-119.

Hertel, G, C Deter and U Konradt (2006). Motivation gains in computer-supported groups1. Journal of Applied Social Psychology, 33(10), 2080-2105.

Hosseini, MR and N Chileshe (2013). Global virtual engineering teams (GVETs): A fertile ground for research in Australian construction projects context. International Journal of Project Management, 31(8), 1101-1117.

Huang, H-C, M-C Lai and T-H Lin (2011). Aligning intangible assets to innovation in biopharmaceutical industry. Expert Systems with Applications, 38(4), 3827-3834.

Jackson, SE and A Joshi (2004). Diversity in social context: A multi-attribute, multilevel analysis of team diversity and sales performance. Journal of Organizational Behavior, 25(6), 675-702.

Kang, I, KC Lee, S Lee and J Choi (2007). Investigation of online community voluntary behavior using cognitive map. Computers in Human Behavior, 23(1), 111-126.

Kline, RB (2005). Principles and practices of structural equation modeling, 2nd Edition. New York: The Guilford Press.

Lawson, B and D Samson (2001). Developing innovation capability in organisations: A dynamic capabilities approach. International Journal of Innovation Management, 5(3), 377-400.

Lee-Kelley, L and T Sankey (2008). Global virtual teams for value creation and project success: A case study. International Journal of Project Management, 26(1), 51-62.

Lipnack, J and J Stamps (2000). Virtual Teams: People Working Across Boundaries with Technology, 2nd Edition. New York: John Wiley, Sons, Inc.

Luca, LM De and K Atuahene-Gima (2007). Market knowledge dimensions and crossfunctional collaboration: Examining the different routes to product innovation performance. Journal of Marketing, 71(1), 95-112. 
Martinic, A, K Fertalj and D Kalpic (2012). Methodological framework for virtual team project management. International Journal of Innovation, Management and Technology, 3(6), 702.

Martins, LL, FJ Milliken, BM Wiesenfeld and SR Salgado (2003). Racioethnic diversity and group members' experiences: The role of the racioethnic diversity of the organizational context. Group and Organization Management, 28(1), 75-106.

Matthew, C and R Sternberg (2006). Leading innovation through collaboration. Emerald Group Publishing Limited, 12, 27-52.

McKnight, DH, LL Cummings and NL Chervany (1995). Trust formation in new organisational relationships. Information and Decision Sciences Workshop, University of Minnesota.

Meyer, JP and NJ Allen (1991). A three-component conceptualization of organizational commitment: Some methodological considerations. Human Resource Management Review, 1, 61-98.

Meyer, J and L Herscovitch (2002). Commitment in the workplace: Toward a general model. Human Resource Management Review, 11(3), 299-326.

Milliken, F and L Martins (1996). Searching for common threads: Understanding the multiple effects of diversity in organizational groups. Academy of Management Review, 21, 402-433.

Montoya, M, M Massey, AP Hung, Y-T Caisy and CB Crisp (2009). Can you hear me now? Communication in virtual product development teams. Journal of Product Innovation Management, 26(2), 139-155.

Moynihan, LM, RS Peterson and PC Earley (2006). Cultural intelligence and the multinational team experience: Does the experience of working in a multinational team improve cultural intelligence? National Culture and Groups, 9, 299-323.

Nissen, HA, MR Evald and AH Clarke (2014). Knowledge sharing in heterogeneous teams through collaboration and cooperation: Exemplified through public-privateinnovation partnerships. Industrial Marketing Management, 43(3), 473-482.

Nunnally, JC (1978). Psychometric Theory (2nd ed.). New York, NY: McGraw-Hill.

O'Leary, M and J Cummings (2007). The spatial, temporal, and configurational characteristics of geographic dispersion in teams. MIS Quarterly, 31(3), 433-452.

Ostergaard, CR, B Timmermans and K Kristinsson (2011). Does a different view create something new? The effect of employee diversity on innovation. Research Policy, 40(3), 500-509.

Pearce, CL and PA Herbik (2004). Citizenship behavior at the team level of analysis: The effects of team leadership, team commitment, perceived team support, and team size. The Journal of Social Psychology, 144(3), 293-310.

Peters, LM and CC Manz, (2007). Identifying antecedents of virtual team collaboration. Team Performance Management: An International Journal, 13(3/4), 117-129.

Piekkari, R and S Tietze (2011). A world of languages: Implications for international management research and practice. Journal of World Business, 46(3), 267-269.

Pinjani, P and P Palvia (2013). Trust and knowledge sharing in diverse global virtual teams. Information and Management, 50(4), 144-153. 
Podsakoff, PM, SB MacKenzie, J-Y Lee and NP Podsakoff (2003). Common method biases in behavioral research: A critical review of the literature and recommended remedies. Journal of Applied Psychology, 88, 879-903.

Pushpa, R and M Mathew (2012). Collaborative behaviour of software product development teams varying on product newness as a surrogate measure for innovation. International Journal of Innovation Management, 16(4), 1250019.

Putnam, RD (2000). Bowling Alone: The Collapse and Revival of American Community. New York: Simon and Schuster. Available at: http://bowlingalone.com/.

Reed, AH and LV Knight (2010). Effect of a virtual project team environment on communication-related project risk. International Journal of Project Management, 28(5), 422-427.

Rogbeer, S, R Almahendra and B Ambos (2014). Open-innovation effectiveness: When does the macro design of alliance portfolios matter? Journal of International Management, 20(4), 464-477.

Rusman, E, V Bruggen, J Sloep and PK Rob (2010). Fostering trust in virtual project teams: Towards a design framework grounded in a TrustWorthiness ANtecedents (TWAN) schema. International Journal of Human-Computer Studies, 68(11), 834-850.

Staples, DS and J Webster (2008). Exploring the effects of trust, task interdependence and virtualness on knowledge sharing in teams. Information Systems Journal, 18(6), 617-640.

Tekleab, AG and NR Quigley (2014). Team deep-level diversity, relationship conflict, and team members' affective reactions: A cross-level investigation. Journal of Business Research, 67(3), 394-402.

Turner, JC, MA Hogg, PJ Oakes, SD Reicher and MS Wetherell (1987). Rediscovering the social group: A self-categorization theory. Rediscovering the Social Group: A SelfCategorization Theory. Oxford: Bl.

Ulbrich, S, F Anker van den, A Luss, C Huber and H Troitzsc (2011). Co-innovation and collaborative networks. Production Planning and Control: The Management of Operations, 22(5-6), 445-446.

Vaccaro, A, F Veloso and S Brusoni (2009). The impact of virtual technologies on knowledge-based processes: An empirical study. Research Policy, 38(8), 1278-1287.

Van der valk, T, MMH Chappin and GW Gijsbers (2011). Evaluating innovation networks in emerging technologies. Technological Forecasting and Social Change, 78(1), 25-39.

Van Knippenberg, D, CKW De Dreu and AC Homan (2004). Work group diversity and group performance: an integrative model and research agenda. Journal of Applied Psychology, 89(6), 1008.

van Knippenberg, D, WP van Ginkel and AC Homan (2013). Diversity mindsets and the performance of diverse teams. Organizational Behavior and Human Decision Processes, 121(2), 183-193.

Vera, D and M Crossan (2005). Improvisation and innovative performance in teams. Organization Science, 16(3), 203-224.

Winkler, VA and RB Bouncken (2011). How does cultural diversity in global innovation teams affect the innovation process? Engineering Management Journal, 23(4), 24-35. 
Worley, J, L Bailey, R Thompson, K Joseph and C Williams (1999). Organizational communication and trust in the context of technology change. National Technical Information U.S. Department of Transportation Federal Aviation Administration, 1. Yap, C-M, K-H Chai and P Lemaire (2005). An empirical study on functional diversity and innovation in SMEs. Creativity and Innovation Management, 14(2), 176-190.

Zakaria, N, Amelincks, A and W David (2004). Working together apart? Building a knowledge-sharing culture for global virtual teams. Creativity and Innovation Management, 13(1), 15-29. 